\title{
Regulation of the development of flight muscles in long-winged adults of the flightless bug Pyrrhocoris apterus (Heteroptera: Pyrrhocoridae)
}

\author{
RADOMÍR SOCHA and JAN ŠULA \\ Biology Centre ASCR, Institute of Entomology, Branišovská 31, CZ-370 05 České Budějovice, Czech Republic; \\ e-mail:socha@entu.cas.cz
}

\begin{abstract}
Key words. Heteroptera, Pyrrhocoridae, Pyrrhocoris apterus, allatectomy, de-alation, diapause, flight muscles, methoprene, proteins, reproductive organs, starvation, firebug
\end{abstract}

\begin{abstract}
We studied the development of the indirect flight muscles and reproductive organs in long-winged (macropterous) adults of the flightless bug Pyrrhocoris apterus (L.) and the factors involved in flight muscles histolysis by means of total protein analysis. Both the extirpation of the corpus allatum, an endocrine gland that is the sole source of juvenile hormone, and sham operation accelerated histolysis and decreased the level of the total protein content of the flight muscles to the same extent. Degeneration of flight muscles was not a result of allatectomy but rather a consequence of injury, followed by resumption of enhanced food intake, because it was stimulated also by the removal of wings. Transfer of penultimate instar larvae to a diapause-inducing short-day photoperiod did not prevent imaginal growth and histolysis of flight muscles, but inhibited growth of ovaries in females and maturation of accessory glands in adult males. Thus inactivation of the corpus allatum in diapausing macropters does not prevent imaginal growth of their flight muscles. Application of a high dose of methoprene to the surface of intact long-day macropterous adults induced precocious histolysis of flight muscles and growth of ovaries in females and accessory glands in males. Prolonged starvation of macropterous adults had only a small effect on the histolysis of their flight muscles. The results indicate that imaginal growth and histolysis of indirect flight muscles in macropterous individuals of $P$. apterus are largely juvenile hormone-independent processes that are programmed to occur spontaneously, but can be affected by various internal and external factors.
\end{abstract}

\section{INTRODUCTION}

The possession of wings and ability to disperse by flight are important features of insects and have played a key role in their evolutionary success (Roff \& Fairbairn, 1991; Kingsolver \& Koehl, 1994). Wing polymorphism is a common phenomenon in insects and is the most commonly studied type of dispersal polymorphism and the focus of many reviews (Harrison, 1980; Dingle, 1985; Pener, 1985; Roff, 1990; Rankin \& Burchsted, 1992; Zera \& Denno, 1997). An important finding of the studies on wing polymorphism is that dispersal capability has physiological and fitness costs. Fully winged females typically begin egg development later and have reduced fecundity relative to short-winged or wingless females. The wing-polymorphic insects are characterized not only by variation in wing length, but also differ in flightmuscle characteristics. Flight muscles are usually reduced in the flightless morph (Smith, 1964; Marden, 2000) and muscle reduction is thought to be more important than wing reduction in elevating the fecundity of the flightless morph (Zera \& Denno, 1997). Reduction of flight muscles may result from arrested development or from degeneration of originally functional muscles, and is not restricted to short-winged (brachypterous) morphs, since many long-winged (macropterous) species are polymorphic for flight muscle development (Harrison, 1980; Zera \& Denno, 1997).

However, some insect species have evolved flightlessness and neither macropterous nor the brachypterous individuals of these insects fly (Roff, 1990; Roff \& Fairbairn,
1991). The firebug Pyrrhocoris apterus (L.) is a typical representative of this group of wing-polymorphic insects (Socha \& Zemek, 2000a). It is a widely distributed Palaearctic heteropteran species, whose wing polymorphism and reproductive diapause are controlled by photoperiod and temperature (Hodek, 1968; Honěk, 1976; Socha, 2001). Macropterism in this bug is controlled by a recessive allele whose expression is favoured by a long-day photoperiod and high temperature (Honěk, 1976, 1981). More details of $P$. apterus biology can be found in a review published by Socha (1993). Recently, we showed that $P$. apterus is polymorphic for wing length and flight muscle development. The macropterous adults of both sexes have fully developed flight muscles (Socha \& Šla, 2006). Despite this, they are unable to fly and have changed their mode of dispersal from flying to walking (Socha \& Zemek, 2000b, 2003). Flight muscles of macropterous males and females of this bug are maintained during their dispersal by walking, but later are histolyzed (Socha \& Šula, 2006), as in many flight-capable wing-polymorphic insects. These authors show that fully developed wings and flight muscles are preserved and flight muscles subsequently histolyzed not only in flying wing-polymorphic insects exhibiting the "oogenesisflight" syndrome (Johnson, 1969; Zera \& Denno, 1997; Lorenz, 2007), but also in insects with a non-functional macropterism and characterized by an "oogenesiswalking" syndrome (Socha, 2004). However, the main factors that play a role in the growth, maintenance and histolysis of flight muscles in insects with non-functional 
macropterism are unknown. $P$. apterus, as a representative of this group of insects, appeared to be a suitable model for this kind of research.

The main aim of the present study was to find what internal and external factors are involved in the growth and degeneration of indirect flight muscles in adult macropterous males and females of $P$. apterus in order to better understand the functional aspects and regulatory mechanisms of growth and degeneration of flight muscles in this flightless wing-polymorphic species.

\section{MATERIAL AND METHODS}

\section{Experimental insects}

Macropterous adults of Pyrrhocoris apterus (L.) were used in all the experiments. The macropterous culture of this bug was established from adults collected from the field near České Budějovice (Czech Republic, 48 ${ }^{\circ} 59^{\prime} \mathrm{N}, 1^{\circ} 28^{\prime} \mathrm{E}$ ). All stages, from egg to adult, were kept in glass jars $(0.51)$ supplied with linden seeds (Tilia cordata Miller) for food and water ad libitum at a constant temperature of $26 \pm 1{ }^{\circ} \mathrm{C}$. The culture was maintained under a diapause-preventing long-day $(18 \mathrm{~L}: 6 \mathrm{D})$ photoperiod that allowed continuous breeding (Socha et al., 1998). The long-day macropterous females have about a two week longer pre-oviposition period than the long-day brachypterous females (Socha \& Šula, 1996).

Larvae and adults were kept in mass culture (approximately 40 specimens per jar), and food and water were replenished twice a week. Freshly emerged adults of macropterous morph were removed from the culture, separated according to sex and then transferred in groups of 10-20 specimens into small glass jars $(250 \mathrm{ml})$. They were kept either under the same photoperiodic and temperature regimes as they developed in or transferred to a diapause-inducing short-day $(12 \mathrm{~L}: 12 \mathrm{D})$ photoperiod and constant temperature of $26 \pm 1{ }^{\circ} \mathrm{C}$. In starvation experiments, the freshly emerged adults were either starved for 21 days or initially allowed to feed for the first five days of their adult life, and then starting on day 6 they were only supplied with water.

The following experimental groups of macropterous adults were used in our experiments: de-alated, starved, allatectomized, sham-operated, methoprene-treated and diapausing bugs.

\section{Sample preparation}

Experimental and control macropterous adults of particular ages were sampled for determination of total protein content in the flight muscles, ovaries, testes and accessory glands. The organs were dissected in ice-cold isotonic Ringer saline $(0.13 \mathrm{M}$ $\mathrm{NaCl}, 1.3 \mathrm{mM} \mathrm{KCl}, 2.4 \mathrm{mM} \mathrm{NaHCO}_{3}$ and $1.8 \mathrm{mM} \mathrm{CaCl}_{2}$ ), transferred into separate micro tubes, and stored at $-40^{\circ} \mathrm{C}$ until used.

\section{Protein determination}

Samples of dissected organs were individually homogenized by sonication in $80 \mu 1$ of $0.1 \mathrm{M}$ Tris- $\mathrm{HCl}$ buffer $\mathrm{pH} 7.5$ (Ultrasonic Homogenizer, Cole-Parmer Instrument Co.). The homogenates were centrifuged at $6,000 \mathrm{~g}$ for $5 \mathrm{~min}$. and supernatants were used for subsequent analysis. The concentration of proteins in the homogenates of dorsolongitudinal flight muscles (DFM), ovaries, testes and accessory glands was determined by the bicinchoninic acid method according to Stoscheck (1990). The optical density was measured at $562 \mathrm{~nm}$ on a SpectraMax 340 PC reader (Molecular Devices) using bovine serum albumin (BSA) as a standard. As we observed no significant differences in the fresh weights of ovaries and dorsolongitudinal muscles $(1.49 \pm 0.23 \mathrm{mg}$ and $4.07 \pm 0.48 \mathrm{mg}$, respectively) in 10 day old macropterous females (unpubl. data), the total protein content is not presented as amount of protein per mg fresh weight but as the amount of protein per whole organ.

\section{Surgical procedures and experimental treatments}

The effects of various internal and external factors (de-alation, starvation, allatectomy, juvenile hormone analogue treatment and diapause-inducing photoperiod) on the total protein content of DFM and reproductive organs were studied by means of the following surgical procedures and experimental treatments.

\section{De-alation}

Artificial removal of the fore- and hind-wings of macropterous adult males and females was performed on the day of adult emergence.

\section{Starvation}

While the 7-14 day old brachypterous adults feed normally (Socha et al., 1997), macropterous adults of the same age fast spontaneously (Socha et al., 1998; Socha \& Zemek, 2007). To determine whether the imaginal growth and histolysis of DFM in macropterous adults can be inhibited or at least postponed by artificial starvation, two different starvation experiments were performed. In the first experiment, freshly emerged macropterous adults were supplied with water and kept without linden seeds until day 21 of their adult life, when the total protein contents of their DFM and reproductive organs were determined. In the second experiment, the freshly emerged macropterous males and females were initially allowed to feed on linden seeds for the first five days of their adult life. Afterwards, they were supplied with water only and kept without linden seeds until day 21 after adult emergence, when the total protein contents of their tissues were determined.

\section{Allatectomy}

To study the effect of juvenile hormone (JH) on flight muscle histolysis and the growth of ovaries, the corpus allatum (CA), the source of JH in insects, was excised. Freshly emerged macropterous females that were deprived of food were operated within $48 \mathrm{~h}$ of adult emergence. An incision in the neck membrane was made under insect saline and the CA excised together with a piece of aorta. As a control, only the aorta was transected in sham-operated adult females of the same wing morph. The effects of CA extirpation on the total protein content of flight muscles and ovaries were determined at 7 and 21 days.

\section{Methoprene treatment}

Sláma et al. (1974) describe and test many natural and synthetic substances that have $\mathrm{JH}$ activity in $P$. apterus. In the present study, we used one of the most active analogues of juvenile hormone (JHa), methoprene, prepared in the Institute of Organic Chemistry and Biochemistry of the Czech Academy of Sciences, Prague. To study the effects of the high titre of JH on the histolysis of DFM in macropterous males and females, we treated them topically with $2 \mu \mathrm{l}$ of acetone solution containing methoprene $(1 \mu \mathrm{g} / \mathrm{ml})$ on the $3 \mathrm{rd}$ and 7 th day after adult emergence and the effects were determined on day 10 after adult emergence. Adults of the same age used as controls were treated with $2 \mu \mathrm{l}$ of acetone only on the 3rd and 7th day after adult emergence. To study the effect of $\mathrm{JH}$ on the growth of flight muscles in allatectomized macropterous females, they were treated within $24 \mathrm{~h}$ of the operation with $1 \mu \mathrm{l}$ of acetone solution containing either a low $(0.5 \mathrm{ng}$ or $20 \mathrm{ng})$ or high $(2 \mu \mathrm{g})$ dose of methoprene. Then, the total protein content of DFM and ovaries of 7 day old allatectomized + methoprene-treated females was 


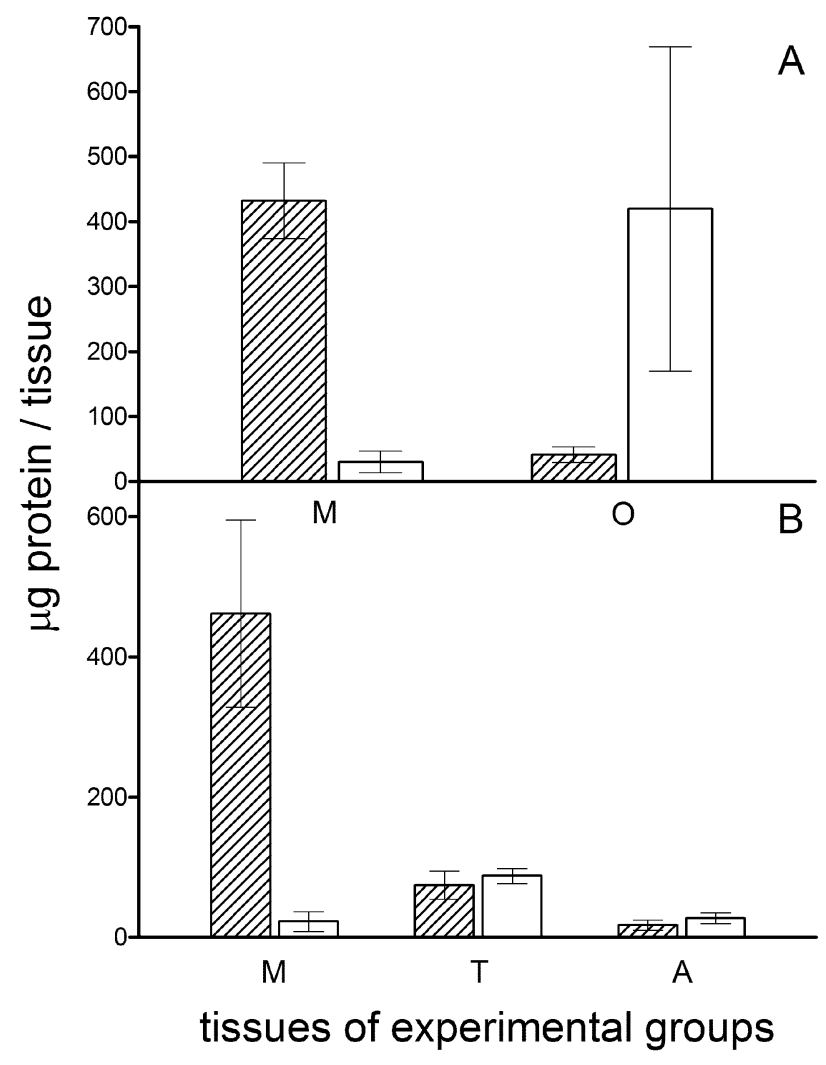

Fig. 1. The effect of de-alation on the total protein content of the dorsolongitudinal flight muscles and reproductive organs of long-day macropterous females (A) and males (B) of $P$. apterus. Hatched bars - 10 day old intact adults (controls), empty bars 10 day old de-alated adults. $\mathrm{M}$ - dorsolongitudinal flight muscles, $\mathrm{O}$ - ovaries, $\mathrm{T}-$ testes, $\mathrm{A}-$ accessory glands. Error bars indicate $\mathrm{SD} ; \mathrm{n}=8-15$.

determined and compared with that of allatectomized + acetone treated macropterous females of the same age.

Diapause-inducing photoperiod

To study the effect of a short-day photoperiod, which induces reproductive diapause and inactivity of the CA (Hodek, 1968; Sláma et al., 1974; Hodková, 1976), on the growth and histolysis of DFM, freshly emerged macropterous adults were transferred from a long-day $(18 \mathrm{~L}: 6 \mathrm{D})$ to a short-day $(12 \mathrm{~L}$ : 12D) photoperiod and a constant temperature of $26 \pm 1^{\circ} \mathrm{C}$. Later, on days $1,3,5,7,10,14,21$ and 28 , the total protein content of their DFM and reproductive organs was determined. In other experiments, freshly ecdysed larvae of the penultimate (4th) instar were transferred from a long-day (18L : 6D) to a short-day (12L : 12D) photoperiod at a constant temperature of $26 \pm 1^{\circ} \mathrm{C}$, and the total protein content of their DFM and reproductive organs was determined on day 7 and 21 after adult emergence.

\section{Data presentation and statistical analyses}

Statistics were computed using the software GraphPad Prism, version 4.0 (San Diego, CA, USA). For a comparison and determination of the significance of the results, either a two-tailed t-test (Man-Whitney) or a one-way analysis of variance (ANOVA) followed by Tukey's multiple comparison test were used.

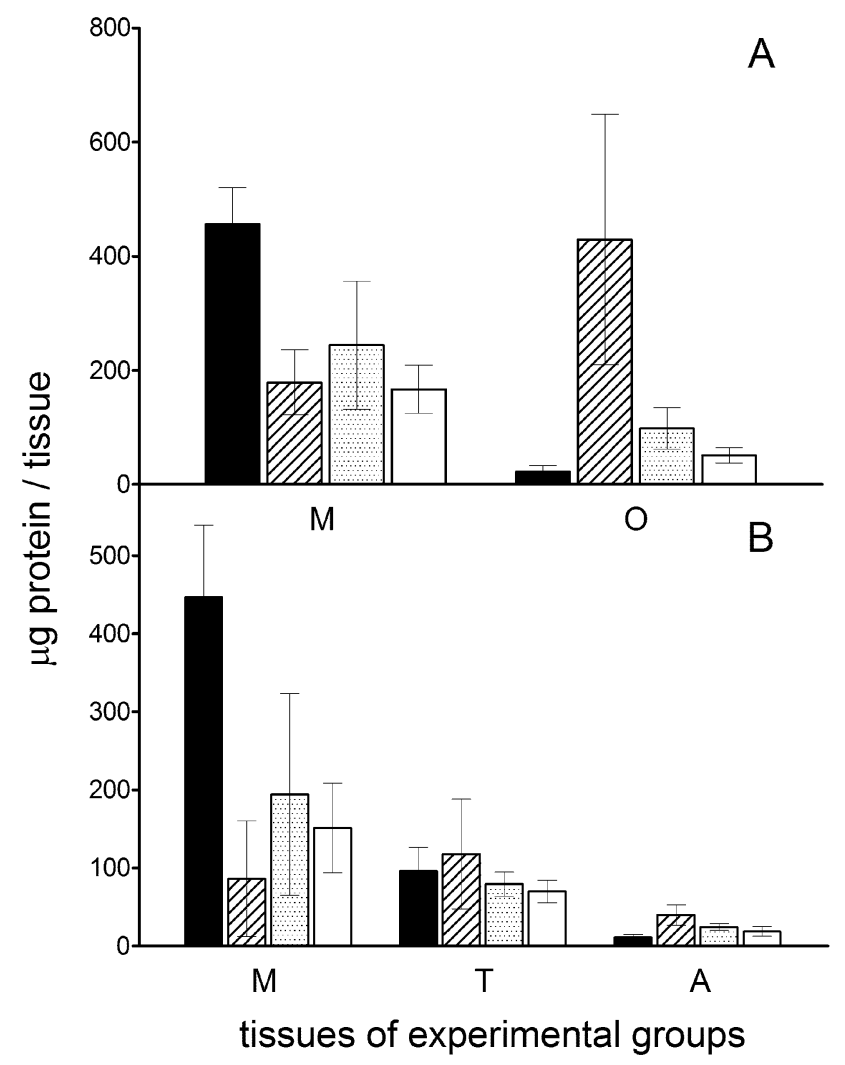

Fig. 2. The effect of prolonged starvation on the total protein content of the dorsolongitudinal flight muscles and reproductive organs of long-day macropterous females (A) and males (B) of P. apterus. Black bars -7 day old fed adults, hatched bars -21 day old fed adults, dotted bars -21 day old adults starved from day 6 after adult emergence, empty bars -21 day old adults starved from adult emergence. $\mathrm{M}$ - dorsolongitudinal flight muscles, $\mathrm{O}-$ ovaries, $\mathrm{T}-$ testes, $\mathrm{A}-$ accessory glands. Error bars indicate $\mathrm{SD} ; \mathrm{n}=7-20$.

\section{RESULTS}

\section{De-alation}

De-alation of macropterous males and females accelerated the histolysis of the DFM, which was accompanied by a substantial decrease in their total protein content and increase in that in the ovaries and accessory glands (Fig. 1A, B). The total protein content of DFM in 10 day old de-alated adults $(22.7 \pm 14.1 \mu \mathrm{g}$ in males and $30.4 \pm 16.7$ $\mu \mathrm{g}$ in females) was significantly lower $(P<0.0001)$ than in the same-aged intact macropterous adults $(461.8 \pm 34.4$ $\mu \mathrm{g}$ in males and $432.0 \pm 18.4 \mu \mathrm{g}$ in females). The 10 day old de-alated and control adults significantly differed also in the total protein content of their ovaries $(419.5 \pm 176.3$ $\mu \mathrm{g}$ vs. $41.4 \pm 3.8 \mu \mathrm{g}, P<0.0001)$ and accessory glands $(27.2 \pm 2.5 \mu \mathrm{g}$ vs. $17.6 \pm 7.4 \mu \mathrm{g}, P<0.003)$ (Fig. $1 \mathrm{~A}, \mathrm{~B})$, but not testes $(87.8 \pm 3.4 \mu \mathrm{g}$ vs. $74.1 \pm 6.5 \mu \mathrm{g})$.

\section{Starvation}

In the first experiment, the macropterous adults were starved from the day of adult emergence and the total protein in their DFM determined on day 21 of their adult life. The total protein content of DFM of these females (166.8 $\pm 42.3 \mu \mathrm{g})$ and males $(151.2 \pm 57.5 \mu \mathrm{g})$ did not differ sig- 


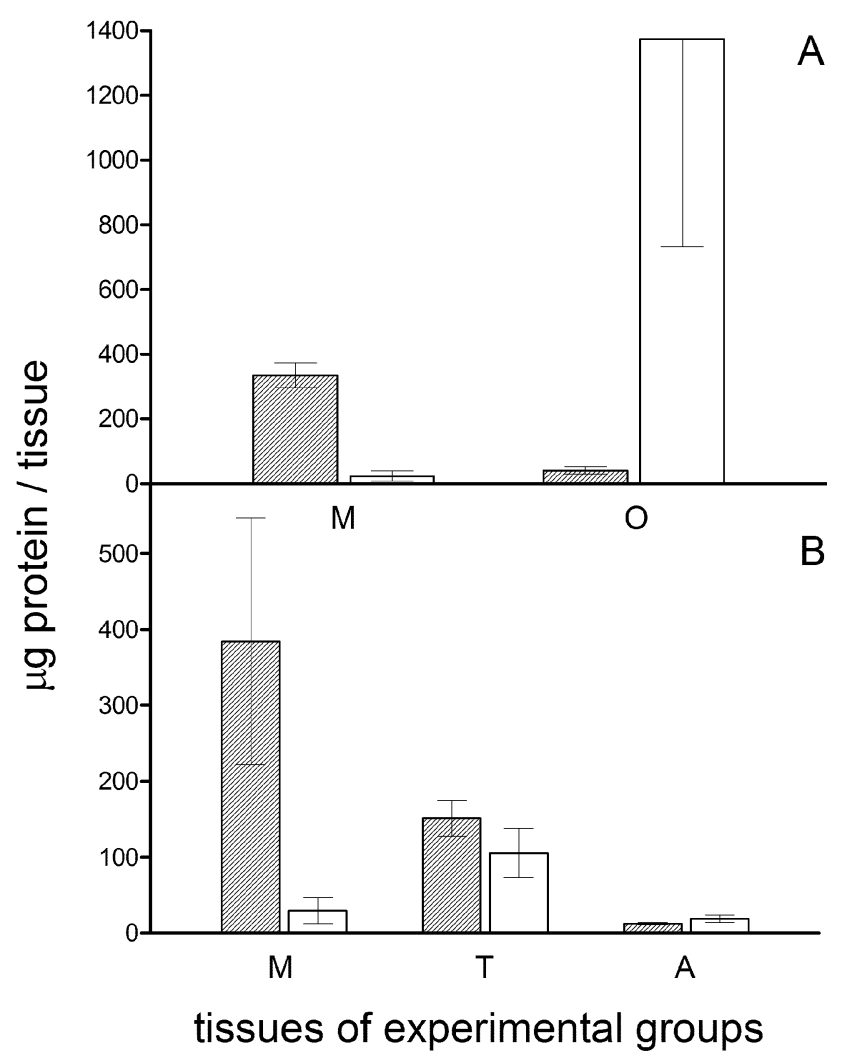

Fig. 3. The effect of methoprene on the long-day macropterous females (A) and males (B) of P. apterus. Hatched bars 10 day old acetone-treated adults (controls), empty bars -10 day old methoprene-treated adults. $\mathrm{M}$ - dorsolongitudinal flight muscles, $\mathrm{O}$ - ovaries, $\mathrm{T}$ - testes, A - accessory glands. Error bars indicate $\mathrm{SD} ; \mathrm{n}=8-10$.

nificantly (at $P<0.05$ ) from that of the flight muscles of macropterous females $(178.8 \pm 57.1 \mu \mathrm{g})$ and males $(86.2$ $\pm 74.2 \mu \mathrm{g}$ ) of the same age that were fed (Fig. 2A, B). The total protein content of the ovaries of macropterous adults starved for 21 days was significantly lower $(P<$ $0.0001)$ than that of the same-aged but fed controls, and significantly higher $(P<0.0001)$ than that of 7 day old non-starved control females. As in the testes, the total protein content of the accessory glands of macropterous adult males starved for 21 days $(18.8 \pm 6.5 \mu \mathrm{g})$ was significantly lower $(P=0.0003)$ than that recorded for the same-aged non-starved controls $(39.6 \pm 13.1 \mu \mathrm{g})$ (Fig. 2B).

To determine the effect of prolonged starvation on the histolysis of already developed flight muscles in macropterous adults, they were fed for the first five days of adult life and then starved from sixth to 21 st day. The total protein content of DFM of 21 day old macropterous males $(194.1 \pm 129.4 \mu \mathrm{g})$ and females $(244.5 \pm 111.7 \mu \mathrm{g})$ starved from day 6 after adult emergence were higher than in the same-aged but fed macropterous males (86.2 \pm $74.2 \mu \mathrm{g})$ and females $(178.8 \pm 57.1 \mu \mathrm{g})$, but the difference was significant $(P=0.007)$ only in males (Fig. $2 \mathrm{~A}$, B). The percentage of specimens with well histolyzed flight muscles was also somewhat lower in starved macropterous adults (55\% in males and $60 \%$ in females) than

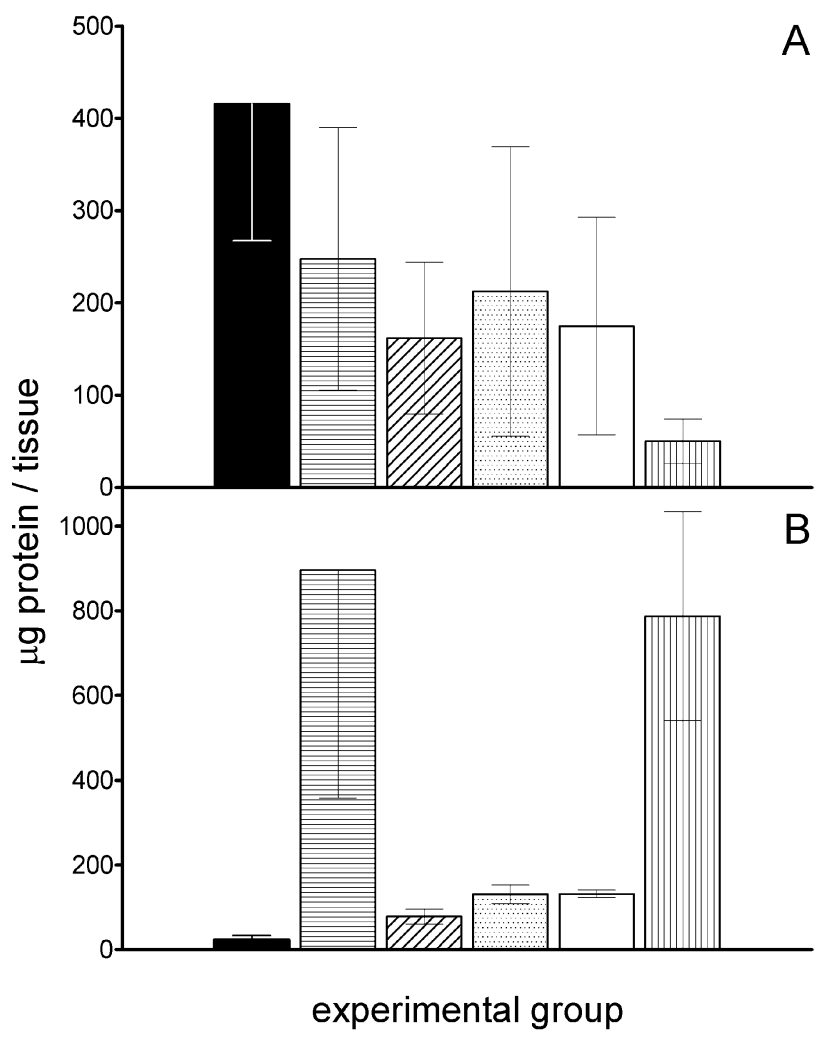

Fig. 4. The effect of allatectomy and allatectomy+methoprene treatment on the dorsolongitudinal flight muscles (A) and ovaries (B) of long-day macropterous adult females of $P$. apterus. Black bars -7 day old fed females, horizontally dashed -7 day old sham-operated females, hatched bars -7 day old allatectomized females treated with acetone only, dotted bars -7 day old allatectomized females treated with $0.5 \mathrm{ng}$ methoprene, empty bars - 7 day old allatectomized females treated with $20 \mathrm{ng}$ methoprene, vertically dashed bars -7 day old allatectomized females treated with $2 \mu \mathrm{g}$ methoprene. Error bars indicate SD; $\mathrm{n}$ $=5-10$.

in non-starved macropterous controls $(85 \%$ in males and $75 \%$ in females) of the same age. The results indicate that prolonged starvation slightly suppresses the histolysis of indirect flight muscles in $P$. apterus.

\section{Methoprene treatment}

Treatment of 3 and 7 day old intact macropterous males and females with a high dose $(2 \mu \mathrm{g})$ of methoprene induced precocious histolysis of DFM and decreased their total protein content (Fig. 3). An accelerated degradation of DFM in 10 day old methoprene-treated adults was associated with a significant increase $(P<0.001)$ in the total protein content of the ovaries of females $(1374.0 \mu \mathrm{g})$ and accessory glands of males $(19.0 \mu \mathrm{g})$ compared to that of acetone-treated females and males of the same age (41.4 and $12.5 \mu \mathrm{g})$ (Fig. 3A, B). The total protein content of the DFM of 10 day old methoprene-treated macropterous adults $(29.9 \pm 17.4 \mu \mathrm{g}$ in males and $23.8 \pm 15.1 \mu \mathrm{g}$ in females) was significantly lower $(P<0.0001$ in both males and females) than in the same-aged acetone-treated macropterous adults $(384.1 \pm 162.5 \mu \mathrm{g}$ in males and $334.4 \pm 38.3 \mu \mathrm{g}$ in females) and was approximately the same as that recorded in 21 day old intact macropterous 


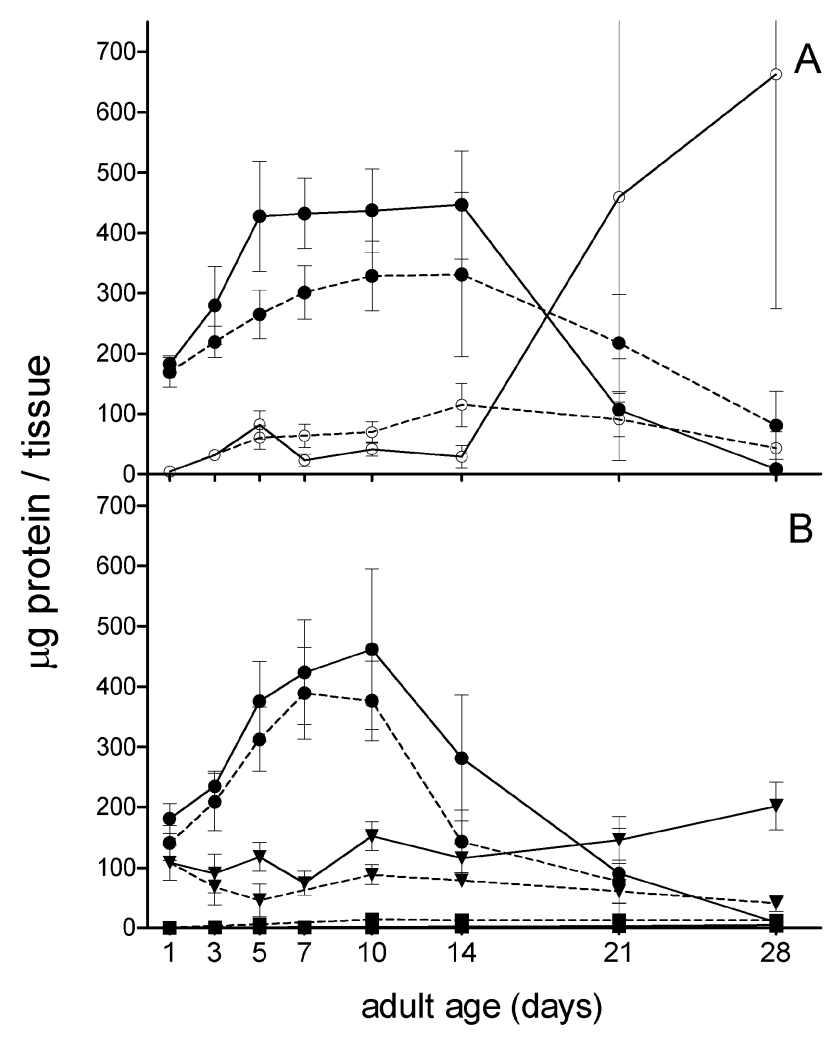

Fig. 5. Temporal changes in the total protein content of the dorsolongitudinal flight muscles and reproductive organs of 1-28 days old macropterous females (A) and males (B) of $P$. apterus. Solid line - long-day control adults, dashed line adults transferred at emergence from a long-day $(18 \mathrm{~L}: 6 \mathrm{D})$ to a short-day (12L : 12D) diapause-inducing photoperiod, $\bullet-$ dorsolongitudinal flight muscles, $\bigcirc-$ ovaries, $\mathbf{\nabla}$ - testes, $\mathbf{-}$ - accessory glands. Error bars indicate SD; $n=10-20$.

bugs (Fig. 1A, B). These results indicate the important role of $\mathrm{JH}$ in the acceleration of histolysis of indirect flight muscles in this bug.

\section{Allatectomy and methoprene treatment}

A major step in identifying the role of $\mathrm{JH}$ in imaginal growth and histolysis of DFM in macropterous adults was expected from the results of the allatectomy of macropterous females and allatectomy + methoprene treatments. However, our study revealed that both the sham-operation and allatectomy induced a significant decrease in the total protein content of DFM in 7 day old allatectomized $(P=$ $0.005)$ and sham-operated $(P=0.006)$ females (Fig. $4 \mathrm{~A})$ compared to control females of the same age. A significant decrease in the total protein content of DFM was found also in 21 day old allatectomized macropterous females $(P=0.014$; data not shown) compared to control females of the same age. The results showed that histolysis of DFM can be induced not only in de-alated bugs, but also in injured non-allatectomized individuals. Treating allatectomized females with applications of 0.5 ng or $2 \mathrm{ng}$ methoprene (Fig. 4B) and other low doses of this JHa (unpubl. data) did not restore the total protein content of DFM in 7 day old macropterous females to that recorded in same-aged intact macropterous females (Fig.

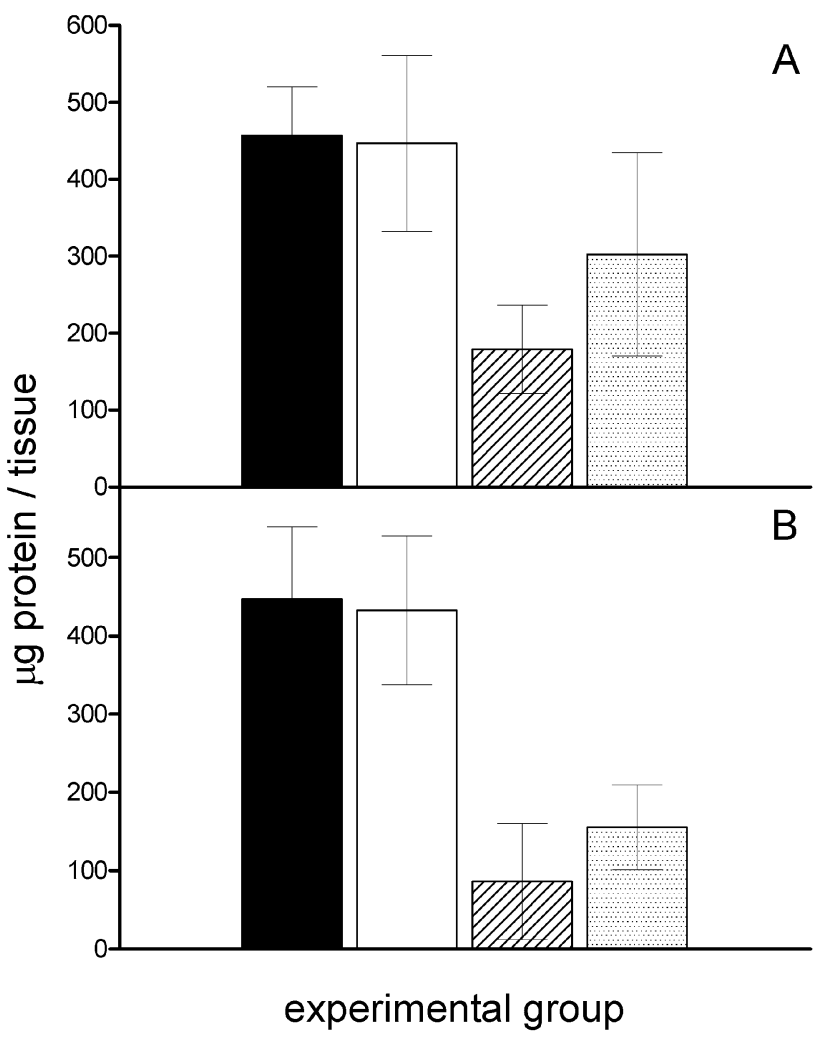

Fig. 6. The total protein content of the dorsolongitudinal flight muscles of adult macropterous females (A) and males (B) of $P$. apterus transferred from a long-day $(18 \mathrm{~L}: 6 \mathrm{D})$ to a short-day (12L : 12D) diapause-inducing photoperiod at the beginning of the penultimate (4th) larval instar. Black bars -7 day old long-day macropterous adults, empty bars -7 day old macropterous adults transferred to short-day (SD) conditions as larvae, hatched bars -21 day old long-day macropterous adults, dotted dashed bars -21 day old macropterous adults transferred to SD as larvae. Error bars indicate SD; $n=10-12$.

4A). On the other hand, the total protein content of the ovaries of 7 day old allatectomized macropterous females treated with $2 \mathrm{mg}$ methoprene on the day of adult emergence was almost as high $(787.5 \pm 100.1 \mu \mathrm{g})$ as that of 7 day old sham-operated acetone-treated females (896.6 \pm $190.7 \mu \mathrm{g})$, but significantly $(P<0.0001)$ higher than in the same-aged allatectomized+acetone-treated controls $(77.4 \pm 10.1 \mu \mathrm{g})$ (Fig. 4B).

\section{Diapause-inducing photoperiod}

Since the above results showed that the histolysis of DFM is similarly induced in sham-operated and allatectomized females, we attempted to identify the role of $\mathrm{JH}$ in imaginal growth and histolysis of DFM in macropterous adults by inhibiting the CA without injuring the bugs. We tested whether the growth and histolysis of DFM in macropterous bugs can be affected by transferring them to a short-day photoperiod that is known to inhibit the CA and induce reproductive diapause in P. apterus (Hodek, 1968; Hodková, 1976). The experiments showed that imaginal growth and histolysis of DFM in 21 day old males (Fig. A) and females (Fig. 5B) of the macropterous morph were not prevented when they were transferred as freshly 
emerged adults from a long-day (18L : 6D) to a short-day (12L : 12D) photoperiod.

To be sure that activity of the CA was completely inhibited by the diapause-inducing photoperiod, the freshly ecdysed larvae of the penultimate (4th) instar were transferred from a long-day (18L : 6D) to short-day (12L : 12D) photoperiod at the same temperature (Fig. 6). The total protein content of DFM of 7 day old adults $(432.6 \pm 21.3 \mu \mathrm{g}$ in males and $446.9 \pm 38.1 \mu \mathrm{g}$ in females) that developed at a short-day photoperiod from the beginning of the 4th larval instar did not significantly differ from that found in 7 day old long-day macropterous adults $(446.6 \pm 29.3 \mu \mathrm{g}$ in males and $456.7 \pm 20.0 \mu \mathrm{g}$ in females). A significant decrease in the protein content of DFM was observed in 21 day old males $(155.4 \pm 19.2 \mu \mathrm{g}$, $P<0.0001)$ and females $(302.3 \pm 38.2 \mu \mathrm{g}, P=0.0167)$ exposed to a short-day photoperiod from the beginning of the 4th larval instar compared to 7 day old males and females that developed from 4th instar larvae transferred from a long-day to a short-day photoperiod (see above). Nevertheless, in males and females the protein content of the flight muscles of 21 day old animals was found to be significantly higher under SD-conditions than under LDconditions ( $P=0.025$ and 0.013 , respectively) (Fig. 6). These results indicate that cessation of CA activity in macropterous adults of $P$. apterus did not prevent imaginal growth of indirect flight muscles. In 21 day old bugs reared under LD-conditions the subsequent flight muscle histolysis was slightly accelerated due to $\mathrm{JH}$ stimulated growth of reproductive organs.

\section{DISCUSSION}

\section{The effects of de-alation and feeding on the development of the flight muscles}

The present study showed that histolysis of flight muscles in both sexes of macropterous adults of P. apterus can be induced and accelerated by de-alation. Induction of flight muscle histolysis by de-alation is recorded also for long-winged adults of the crickets Modicogryllus confirmatus (Tanaka, 1994) and Gryllus bimaculatus (Gomi et al., 1995). Nevertheless, histolysis of flight muscles in macropterous females of $P$. apterus is also induced and accelerated by other kinds of injuries such as shamoperations (Hodková \& Socha, 2006). It should be mentioned, however, that the effect of wing-removal (de-alation) is much stronger than that of a shamoperation. In macropterous females of this bug the stimulating effect of injury is transmitted to the neuroendocrine complex in situ via the nervous system (Hodková \& Socha, 2006). It induces an increase in feeding activity necessary for repairing and healing of injured tissues, and subsequently removes the inhibition of the CA that is temporarily suppressed via nervous connections from the brain in spontaneously fasting macropterous adults (Hodková \& Socha, 2006). Enhanced food intake and activation of CA in de-alated macropterous adults is followed by accelerated histolysis of flight muscles and growth of the reproductive organs. This accords with the finding that the length of the pre-oviposition period in de- alated macropterous females with precociously histolyzing flight muscles is shorter ( 10 days; Socha, 2007) than in intact macropterous females (19-25 days) (Socha \& Šula, 1996; Socha, 2007).

Food intake stimulated the growth and gonadotropic activity of the CA also in long-day brachypterous females of P. apterus (Hodková, 1982). The size of the CA of long-day reproductive brachypterous females with vitellogenic ovaries was found to be about four times larger than that of starving long-day brachypterous females with previtellogenic ovaries (Hodková, 2001). The CA of young spontaneously fasting macropterous females $(<14$ days old) is similar in size to that of starving brachypterous females and its activity is below the threshold for vitellogenesis (Hodková \& Socha, 2006). It is known that feeding serves as a stimulus resulting in the removal of the inhibition of the CA and that it can be transmitted to a transplanted brain-CC-CA complex via the haemolymph (Hodková, 1982). Thus, renewed food intake in older intact macropterous adults of P. apterus ( $>14$ days old) after dispersal reactivates the $\mathrm{CA}$, which triggers and accelerates the breakdown of their indirect flight muscles.

The slower maturation of accessory glands and lower mating success of spontaneously fasting macropterous males ( $<18$ days old) compared to the same-aged brachypterous males that have fed (Socha et al., 2004; Socha, 2006) is also associated with a significantly smaller volume of the CA in the former (Socha \& Hodková, 2006), which accords with the inhibitory effect of starvation on the size and presumed activity of this endocrine gland in P. apterus (Hodková, 1976, 2001). The slight inhibitory effect of prolonged starvation on flight muscle histolysis found in the present study is also supported by the finding that the percentage of specimens with almost fully histolyzed flight muscles was lower in previously starved 18-21 day old macropterous adults than in fed same-aged macropterous controls (Socha \& Sula, unpubl. data). This accords with observations that prolonged starvation of insects leads to cessation of allatal activity (Johansson, 1958; Rankin \& Riddiford, 1977), resulting in a decline in the JH titre in the haemolymph (Tobe \& Chapman, 1979; Weaver \& Pratt, 1981) and inhibits flight muscle histolysis in females of many flying Dysdercus species (Edwards, 1969; Dingle \& Aora, 1973; Nair \& Prabhu, 1979), which belong to the same family Pyrrhocoridae as P. apterus.

\section{The effect of JH and diapause-inducing photoperiod on the flight muscles}

Surgical experiments performed in the present study revealed a decrease in the total protein content of DFM in both 7 day old allatectomized macropterous females and sham-operated controls. Thus, the histolysis of DFM occurred not only after allatectomy but also after a sham operation, as in de-alated bugs. Because the allatectomy and sham-operation of macropterous adults produced similar results, it was not possible to determine the role of $\mathrm{JH}$ in the imaginal growth of indirect flight muscles in $P$. apterus. This question was studied by transferring macropterous bugs (either on day 1 of the penultimate larval 
instar or immediately after adult emergence) from a long-day (18L : 6D) to a short-day (12L : 12D) diapauseinducing photoperiod, which is known to inhibit the CA activity and induce reproductive diapause in this bug (Hodek, 1968; Hodková, 1976). The present study showed that the levels of the total protein in the DFM in 7 day old macropterous adults transferred to a short-day photoperiod at the beginning of the fourth larval instar were as high as those observed in the same-aged macropterous adults that were kept throughout under long-day conditions. Histolysis of DFM in 21 day old macropterous adults that developed from fourth instar larvae transferred to a diapause-inducing photoperiod was also not inhibited. On the other hand, the growth of the reproductive organs in diapausing macropterous adults transferred to a short-day photoperiod was as inhibited (data not shown) as in the short-day diapausing brachypterous adults of $P$. apterus with an inactive CA (Sláma, 1964; Socha \& Hodková, 2006). Thus, flight muscle breakdown was triggered even in short-day diapausing macropterous males and females in which growth of accessory glands or the ovaries were inhibited. Short daylength causes reproductive diapause and flight muscle histolysis also in Colorado potato beetle (Leptinotarsa decemlineata) with an inactive CA (de Kort, 1990). It is very probable that the flight muscle histolysis in short-day diapausing macropterous adults of $P$. apterus found in the present study was triggered by enhanced food intake associated with an accumulation of energy reserves in the fat body, even though CA activity was inhibited and ovarian growth suppressed. Inhibited growth of accessory glands and ovaries in diapausing macropterous adults of this bug is the result of the absence of JH in the body or the presence of a very low titre of this hormone that is below the threshold necessary for the maturation of accessory glands in males and for the growth of vitellogenic oocytes and synthesis of vitellogenin in females (Socha et al., 1991). The volume and activity of CA in short-day diapausing adults are known to be considerably lower than in the same aged long-day adults (Hodková \& Socha, 2006; Socha \& Hodková, 2006). This is in good agreement with our previous studies showing that the growth of reproductive organs is a JH-dependent process (Socha et al., 1991, 2004; Socha, 2006) and related to the size and activity of the CA in both macropterous and brachypterous adults of P. apterus (Hodková \& Socha, 2006; Socha \& Hodková, 2006). Thus, the present study showed that both the growth and histolysis of indirect flight muscles in macropterous individuals of $P$. apterus are $\mathrm{JH}$-independent processes and are not prevented by cessation of CA activity. However, the rate of flight muscle histolysis can be accelerated by $\mathrm{JH}$, because it is higher in 21 day old bugs reared under LD conditions with growing reproductive organs than in bugs of the same age transferred as larvae to $\mathrm{SD}$ conditions, which are in a state of arrested reproduction. This is an important finding because there is currently no data on the hormonal regulation of imaginal growth of the indirect flight muscles in insects (Finlayson, 1975; Marden, 2000). From this point of view, our present results represent the first report documenting that $\mathrm{JH}$ is not necessary for imaginal growth of indirect flight muscles in macropters of P. apterus. However, that some specific neuropeptides synthesized and released from different neurosecretory cells may have a role in the development of flight muscles in this bug can not be excluded.

The present study also shows that the histolysis of indirect flight muscles in $P$. apterus adults can be accelerated by JHa treatment. Programmed cell death involved in the process of flight muscle histolysis in this bug is reported to occur also in some other insects, e.g. the house cricket, Acheta domesticus (Oliver et al., 2007). The JH- or methoprene-induced histolysis of flight muscles is already reported for various flying insects, e.g. the bugs Dysdercus intermedius (Edwards, 1970) and D. cingulatus (Nair \& Prabhu, 1985), beetle Ips confusus (Borden \& Slater, 1968), cricket M. confirmatus (Tanaka, 1994) and aphid Acyrthosiphon pisum (Kobayashi \& Ishikawa, 1994). Histolysis of flight muscles was stimulated by synthetic JH also in the flying pyrrhocorid Dysdercus fulvoniger (Davis, 1975). However, our present results indicate that the hormonal mechanisms involved in induction and acceleration of breakdown of flight muscles in the flying insects are maintained also in the wingpolymorphic insects, which show an evolutionary loss of flight capability.

In summary, the present study shows that the imaginal growth and degeneration of flight muscles can occur in macropterous adults of $P$. apterus with an inactive CA, and the histolysis of their flight muscles can be accelerated by the application of JHa. It appears that imaginal growth and histolysis of flight muscles are genetically programmed processes that occur spontaneously, but can be postponed or accelerated by various internal and external factors, such as injury, starvation, photoperiod and hormonal treatment.

ACKNOWLEDGEMENTS. This study was supported by the Institute project No. Z50070508 from the Academy of Sciences of the Czech Republic and by the grant No. 522/07/0788 from the Grant Agency of the Czech Republic. The authors thank M. Hodková for carrying out the allatectomy of insects and D. Rienesslová for technical assistance.

\section{REFERENCES}

Borden J.H. \& Slater C.E. 1968: Induction of flight muscle degeneration by synthetic juvenile hormone in Ips confusus (Coleoptera: Scolytidae). Z. Vergl. Physiol. 61: 366-368.

DAvis N.T. 1975: Hormonal control of flight muscle histolysis in Dysdercus fulvoniger. Ann. Entomol. Soc. Am. 68: 710-714.

DE Kort C.A.D. 1990: Thirty-five years of diapause research with the Colorado potato beetle. Entomol. Exp. Appl. 56: $1-13$.

Dingle H. 1985: Migration. In Kerkut G.A. \& Gilbert L.I. (eds): Comprehensive Insect Physiology, Biochemistry and Pharmacology. Vol. 9. Pergamon Press, Oxford, pp. 375-415.

Dingle H. \& Arora G. 1973: Experimental studies of migration in bugs of the genus Dysdercus. Oecologia 12: 119-140. 
Edwards F.J. 1969: Development and histolysis of the indirect flight muscles in Dysdercus intermedius. J. Insect Physiol. 15: $1591-1599$.

EDWARDS F.J. 1970: Endocrine control of flight muscle histolysis in Dysdercus intermedius. J. Insect Physiol. 16: 2027-2031.

FINLAYSON L.H. 1975: Development and degeneration. In Usherwood P.N.R. (ed.): Insect Muscle. Academic Press, London, pp. $75-149$.

Gomi T., Okuda T. \& Tanaka S. 1995: Protein synthesis and degradation in the flight muscles of adult cricket (Gryllus bimaculatus). J. Exp. Biol. 198: 1071-1077.

Harrison R.G. 1980: Dispersal polymorphism in insects. Annu. Rev. Ecol. Syst. 11: 95-118.

HodeK I. 1968: Diapause in females of Pyrrhocoris apterus L. (Heteroptera). Acta Entomol. Bohemoslov. 65: 422-435.

HodKovÁ M. 1976: Nervous inhibition of corpora allata by photoperiod in Pyrrhocoris apterus. Nature 263: 521-523.

HodKOVÁ M. 1982: Interaction of feeding and photoperiod in regulation of the corpus allatum activity in females of Pyrrhocoris apterus L. (Hemiptera). Zool. Jb. Physiol. 86: 477-488.

HodKová M. 2001: Regulation of corpora allata in females of Pyrrhocoris apterus (Heteroptera) (a mini-review). In Vitro Cell. Dev. Biol. Anim. 37: 560-563.

HodKovÁ M. \& SOCHA R. 2006: Endocrine regulation of the reproductive arrest in the long-winged females of a flightless bug, Pyrrhocoris apterus (L.). Eur. J. Entomol. 103: 523-529.

HoNĚK A. 1976: Factors influencing the wing polymorphism in Pyrrhocoris apterus (Heteroptera, Pyrrhocoridae). Zool. Jb. Syst. 103: 1-22.

HoNĚK A. 1981: Temperature and wing polymorphism in natural populations of Pyrrhocoris apterus L. (Heteroptera, Pyrrhocoridae). Zool. Jb. Syst. 108: 487-501.

JoHANSSON A.A. 1958: Relation of nutrition to endocrine reproductive functions in the milkweed bug Oncopeltus fasciatus (Dallas) (Heteroptera: Lygaeidae). Nytt. Mag. Zool. 7: 1-132.

Johnson C.G. 1969: Migration and Dispersal of Insect by Flight. Methuen, London, xxii +764 pp.

Kingsolver J.G. \& Koehl M.A.R. 1994: Selective factors in the evolution of insect wings. Annu. Rev. Entomol. 39: 425-451.

Kobayashi M. \& Ishikawa H. 1994: Involvement of juvenile hormone and ubiquitin-dependent proteolysis in flight muscle breakdown of alate aphid (Acyrthosiphon pisum). J. Insect Physiol. 40: 107-111.

LORENZ M.W. 2007: Oogenesis-flight syndrome in crickets: Age-dependent egg production, flight performance, and biochemical composition of flight muscles in adult females Gryllus bimaculatus. J. Insect Physiol. 53: 819-932.

Marden J.H. 2000: Variability in the size, composition, and function of insect flight muscles. Annu. Rev. Entomol. 62: $157-178$.

NaIR C.R.M. \& Prabhu V.K.K. 1979: Effect of starvation, mating, ovariectomy and juvenile hormone analogue on indirect flight muscle histolysis in Dysdercus cingulatus. Entomon 4: 285-288.

NaIR C.R.M. \& Prabhu V.K.K. 1985: Entry of proteins from degenerating flight muscles into oocytes in Dysdercus cingulatus (Heteroptera: Pyrrhocoridae). J. Insect Physiol. 31: 383-388.

Oliver R.H., Albury A.N.J. \& Mousseau T.A. 2007: Programmed cell death in flight muscle histolysis of the house cricket. J. Insect Physiol. 53: 30-39.

Pener M.P. 1985: Hormonal effects on flight and migration. In Kerkut G.A. \& Gilbert L.I. (eds): Comprehensive Insect
Physiology, Biochemistry and Pharmacology. Vol. 8. Pergamon Press, Oxford, pp. 491-550.

RANKIN M.A. \& Burchsted J.C.A. 1992: The cost of migration in insects. Annu. Rev. Entomol. 37: 533-559.

RANKIN M.A. \& RidDIFORD L.M. 1977: Hormonal control of migratory flight in Oncopeltus fasciatus: The effects of the corpus cardiacum, corpus allatum, and starvation on migration and reproduction. Gen. Comp. Endocrinol. 33: 309-321.

RofF D.A. 1990: The evolution of flightlessness in insects. Ecol. Monogr. 60: 389-421.

RofF D.A. \& FaIrbairn D.J. 1991: Wing dimorphisms and the evolution of migratory polymorphisms among the Insecta. Am. Zool. 31: 243-251.

SlÁMA K. 1964: Hormonal control of respiratory metabolism during growth, reproduction, and diapause in male adults of Pyrrhocoris apterus (L.) (Hemiptera). Biol. Bull. 127: 499-510.

SlÁma K., RomaŇuK M. \& Šorm F. 1974: Insect Hormones and Bioanalogues. Springer, New York and Wien, ix $+477 \mathrm{pp}$.

SмITH D.S. 1964: The structure and development of flightless Coleoptera: a light and electron microscope study of the wings, thoracic exoskeleton and rudimentary flight musculature. J. Morphol. 114: 107-183.

Socha R. 1993: Pyrrhocoris apterus (Heteroptera) - an experimental model species: a review. Eur. J. Entomol. 90: 241-286.

SochA R. 2001: Latitudinal gradient in response of wing polymorphism to photoperiod in a flightless bug, Pyrrhocoris apterus (Heteroptera: Pyrrhocoridae). Eur. J. Entomol. 98: $167-169$.

Socha R. 2004: Decreased mating propensity of macropterous morph in a flightless wing-polymorphic insect, Pyrrhocoris apterus L. (Heteroptera). Eur. J. Entomol. 101: 539-545.

SocHA R. 2006: Endocrine control of wing morph-related differences in mating success and accessory gland size in male firebugs. Anim. Behav. 71: 1273-1281.

SochA R. 2007: Factors terminating ovarian arrest in longwinged females of a flightless bug, Pyrrhocoris apterus (Heteroptera: Pyrrhocoridae). Eur. J. Entomol. 104: 15-22.

SochA R. \& HoDKovÁ M. 2006: Corpus allatum volumedependent differences in accessory gland maturation in longand short-winged males of Pyrrhocoris apterus (Heteroptera: Pyrrhocoridae). Eur. J. Entomol. 103: 27-32.

Socha R. \& Šula J. 1996: Differences in haemolymph proteins in relation to diapause and wing dimorphism in Pyrrhocoris apterus (L.) (Heteroptera: Pyrrhocoridae). J. Comp. Physiol. (B) 166: 382-387.

Socha R. \& ŠUla J. 2006: Flight muscles polymorphism in a flightless bug, Pyrrhocoris apterus (L.): Developmental pattern, biochemical profile and endocrine control. J. Insect Physiol. 52: 231-239.

Socha R. \& ZemeK R. 2000a: Wing movement behavior in longand short-winged morphs of flightless bug Pyrrhocoris apterus L. (Heteroptera: Pyrrhocoridae). J. Insect Behav. 13: 741-750.

Socha R. \& ZEMEK R. 2000b: Locomotor activity in adult Pyrrhocoris apterus (Heteroptera) in relation to sex, physiological status and wing dimorphism. Physiol. Entomol. 25: 383-389.

Socha R. \& ZEMEK R. 2003: Wing morph-related differences in the walking pattern and dispersal in a flightless bug, Pyrrhocoris apterus (L.) (Heteroptera). Oikos 100: 35-43.

SochA R. \& ZEMEK R. 2007: Temporal pattern of feeding activity in the firebug Pyrrhocoris apterus and its relation to sex, wing dimorphism and physiological state of adults. Physiol. Entomol. 32: 16-25. 
Socha R., Šula J. \& Zemek R. 1997: Feeding, drinking and digestive enzyme activities in short- and long-day females of Pyrrhocoris apterus (Heteroptera). Physiol. Entomol. 22: 161-169.

Socha R., Śula J. \& Zemek R. 1998: Feeding behaviour, digestive physiology and lipid content in macropterous females of Pyrrhocoris apterus (L.) (Heteroptera: Pyrrhocoridae). Physiol. Entomol. 23: 91-96.

Socha R., Šula J. \& Kodrík D. 2004: Wing morph-related differences in developmental pattern of accessory gland proteins in adult males of Pyrrhocoris apterus (L.) and their endocrine control. J. Insect Physiol. 50: 893-901.

Socha R., Šula J., Kodrík D. \& Gelbič I. 1991: Hormonal control of vitellogenin synthesis in Pyrrhocoris apterus (L.) (Heteroptera). J. Insect Physiol. 37: 805-816.

Stoscheck C.M. 1990: Quantitation of proteins. In Deutscher M.P. (ed.): Methods in Enzymology. Vol. 182. Academic Press, London, pp. 50-68.
TANAKA S. 1994: Endocrine control of ovarian development and flight muscle histolysis in a wing dimorphic cricket, Modicogryllus confirmatus. J. Insect Physiol. 40: 483-490.

Tobe S.S. \& Chapman C.S. 1979: The effect of starvation and subsequent feeding on juvenile hormone synthesis and oocyte growth in Schistocerca americana gregaria. J. Insect Physiol. 25: 701-708.

Weaver R.J. \& Pratt G.E. 1981: Effect of starvation and feeding upon corpus allatum activity and oocyte growth in adult female Periplaneta americana. J. Insect Physiol. 27: 75-83.

Zera A.J. \& Denno R.F. 1997: Physiology and ecology of dispersal polymorphism in insects. Annu. Rev. Entomol. 42: 207-231.

Received November 15, 2007; revised and accepted May 19, 2008 